\title{
Advances in the reintroduction of rare and endangered wild plant species
}

\author{
REN Hai ${ }^{*}$, JIAN ShuGuang, LIU HongXiao, ZHANG QianMei \& LU HongFang \\ Key Laboratory of Vegetation Restoration and Management of Degraded Ecosystems, South China Botanical Garden, Chinese Academy of \\ Sciences, Guangzhou 510650, China
}

Received April 27, 2013; accepted December 23, 2013; published online May 12, 2014

\begin{abstract}
Human disturbance and climate change have increased the risk of extinction for rare and endangered wild plant species. One effective way to conserve these rare and endangered species is through reintroduction. In this review, we summarize the advances in wild plant reintroduction from five perspectives: the establishment of reintroduction biology as an important tool for biodiversity conservation; the importance of genetic diversity in reintroduction; reintroduction under global climate change; recruitment limitation in reintroduction; and reintroduction and ecological restoration. In addition, we consider the future of plant reintroduction strategies.
\end{abstract}

reintroduction, global change, genetic diversity, settlement limitation, ecological restoration, reintroduction biology

Citation: $\quad$ Ren H, Jian SG, Liu HX, Zhang QM, Lu HF. Advances in the reintroduction of rare and endangered wild plant species. Sci China Life Sci, 2014, 57: 603-609, doi: 10.1007/s11427-014-4658-6

The formation of a species, its evolution, potential endangerment and extinction largely reflect interactions between the genetic characteristics of the species and the environment. Globally, plant species are disappearing at an unprecedented rate, because of narrow distribution ranges, over-exploitation, habitat degradation, and climate change $[1,2]$. Currently, approximately 20000 of 300000 known vascular plants species are endangered according to the International Union for Conservation of Nature (IUCN). Thus, the Global Strategy for Plant Conservation (GSPC) was issued by countries that participated in the Convention on Biological Diversity (CBD) in 2002 [3]. In China, about $15 \%-20 \%$ of all plant and animal species are threatened, higher than the global mean of $10 \%-15 \%$ [4]. To meet the GSPC targets, China issued China's Strategy for Plant Conservation in 2008. In goal eight of the strategy, $10 \%$ of threatened species should be reintroduced to their original habitats [4].

*Corresponding author (email: renhai@scib.ac.cn)
The three major techniques to plant conservation include in situ and ex situ conservation, and reintroduction. China has protected approximately $65 \%$ of vascular plant communities using in situ conservation techniques in natural reserves and national park systems, and preserved about $60 \%$ of plant species through ex situ conservation in botanical gardens and other ex situ conservation facilities [5,6]. Reintroduction refers to the deliberate establishment of individuals of a species in an area and/or habitat where it has become extirpated. Therefore, reintroduction may be effective at protecting and rescuing extremely small populations [7]. In 2012, China initiated the second national survey on rare and endangered plants and a national program for the conservation of extremely small populations. These projects are expected to conserve plant species by integrating in situ and ex situ conservation, and reintroduction techniques [2].

The relationship between plants and other organisms in natural ecosystems is extremely complicated [1]. A stable community or ecosystem does not easily integrate a new species, even when that species was an original member of 
the ecosystem. The reintroduction of species is difficult because rare and endangered plant species are often unable to adapt to human disturbance and rapid environmental change. However, the reintroduction of rare and endangered species is of great academic and practical significance but successful cases of reintroduction are few [8]. In this paper, we review the advances in the research and practice concerning the reintroduction of rare and endangered plant species, and consider the need for future research.

\section{The biology of reintroduction and the deve- lopment of reintroduction as an important tool for biodiversity conservation}

The reintroduction of species involves the deliberate establishment of individuals of a species in an area and/or habitat where it has become extinct or nearly extinct. The aim is to establish a viable, self-sustaining population that has sufficient genetic resources to adapt to environmental change [7]. The three main concepts of reintroduction are augmentation, restitution and translocation. In augmentation (referred to as reinforcement or enhancement), individuals are added to an existing population, increasing the population size or genetic diversity. In restitution (referred to as reestablishment or restoration), individuals of a species are released into an area where the species formerly inhabited. In translocation (referred to as species introduction), individuals of a species are transferred from the existing distribution area to new areas that are not part of the historic distribution [9-12]. Seddon [13] defined a conservation translocation spectrum that included reintroduction, reinforcement, ecological replacement, assisted colonization and community construction. The first two concepts focus on particular species. The aim is to restore or augment the population at sites within the original historic distribution. The other three concepts focus on the ecosystem, involving introductions of a species into areas that are not part of its original distribution [13].

International convention gives priority to endangered plant species and species with important economic, cultural and ecological value for reintroduction. Reintroduction is the bridge between in situ and ex situ conservation, and is the final goal of ex situ conservation. Procedures and guidelines for reintroductions have been developed by many international organizations including the European Council [14], Botanic Gardens Conservation International [10] and the International Union for Conservation of Nature $[15,16]$. These guidelines describe the objectives of reintroduction; plant species suitable for reintroduction; habitat requirements for reintroduction; plant material requirements for reintroduction; regulation and control of the reintroduced population; management and monitoring of the reintroduced species; reintroduction procedures; criteria for evaluating the success of the reintroduction. China has established a protocol for the reintroduction of rare and endangered plants involving selecting an appropriate target plant species; conducting basic research on species breeding and other aspects of the biology and ecology; reintroducing the species to the wild while developing market-orientated production; enhancing public awareness of conservation; promoting the reintroduction projects throughout the country. This protocol has resulted in the commercialization of several rare and endangered plant species, including the social, ecological, and economic benefits [2].

Polak and Saltz [17] identified 890 papers related to species reintroduction after searching the ISI database during the period of 1980-2009. Worldwide, reintroductions have been attempted for about 700 taxa, with 301 plant species [18]. Maschinski and Haskins [18] evaluated the success of 301 attempted reintroductions for 128 plant taxa using propagule survival, population persistence and nextgeneration recruitment. Approximately $20 \%$ of the projects involved reintroduction, with $30 \%$ involving augmentation. Albrecht et al. [19] analyzed the CPC International Reintroduction Registry (CPCIRR), finding that 49 cases of plant reintroductions had been attempted up to 2009 . They found that $92 \%$ of the populations survived, $76 \%$ reached reproductive maturity, $33 \%$ produced a next-generation and $16 \%$ produced a next-generation with reproductive individuals. The CPCIRR database showed that some reintroduced populations have persisted for $>24$ years. Albrecht et al. [19] indicated that documenting population sustainability required more than four years data, particularly for long-lived perennials. In Australia, Sheean et al. [20] assessed 54 reintroductions of plant species, finding 25 successful and 14 failed cases, where the unsuccessful cases occurred because of ineffective predator control. In China, 42 plant reintroductions were attempted, mainly in botanical gardens. Reintroductions using the following species have been systematically studied in China: Primulina tabacum Hance, Tigridiopalma magnifica C. Chen, Acer yangbiense, and Cycas debaoensis Y.C. Zhong et C. J. Chen. Approximately 60 species have been reintroduced in China without scientific oversight [2]. The recent global increase in the number of reintroduction cases indicates that reintroduction is being increasingly used to counter biodiversity loss [21].

The discipline of species reintroduction is currently considered independent of conservation biology. The development of the field of species reintroduction was recently highlighted in the publication of the following three books: "Restoring diversity: strategies for the reintroduction of endangered plants" [22]; "Reintroduction Biology: Integrating Science and Management" [23]; and "Plant Reintroduction in a Changing Climate: Promises and Perils" [18].

\section{Genetic diversity in reintroduction}

Genetic diversity is an important factor in the reintroduction of rare species, indicating a species ability to adapt to dif- 
ferent future environments. Reintroductions are more likely to succeed long-term if many individuals from different populations are used. In practice, plant reintroductions seldom involve the collection of plant material from multiple sources [18].

Population ecology and metapopulations provide a framework for understanding and achieving genetic diversity in reintroductions. Theoretically, habitat destruction and fragmentation reduce the population size, increasing the isolation of resident species, resulting in reduced migration and gene flow. To survive environmental change, local populations depend on phenotypic plasticity and adaptive genetic differentiation. Consideration of these genetic limitations is important to prevent the extinction of low fitness populations. Those using reintroduction methods should consider removing detrimental genetic variation and increasing gene flow, neutral variation, and adaptive variation. Therefore, the original seed source of reintroduced species should follow the "seed transfer zones" rule. This rule is defined as the geographical regions where individuals (seeds, seedlings, or adults) of native species can be transferred with no detrimental effects on the mean population fitness. This includes if the transplanting of native species individual (seed, seedling, and grown plant) in the species geographical distribution area is harmless. At the genetic scale, we should consider the expanded phenotypic effect because it may affect ecosystem processes ranging from $\mathrm{N}$ mineralization and litter decomposition to the community structure of insect species associated with a particular plant species [24].

Many reintroduction cases have depended on ex situ conservation from botanical gardens. Kang et al. [25] described three potential genetic risks associated with ex situ conservation in botanical gardens. First, the preserved species may lack sufficient genetic representation because of poor sampling. Second, inappropriate planting in the botanical garden, inadequate records and unclear kinships may expose endangered species to genetic confusion, inbreeding and outbreeding depression. Third, artificial selection and habitat conversion may cause the endangered plants to adapt to the ex situ environment, which may differ substantially from their natural environment. Thus, not recognizing these genetic issues, ex situ conservation will not provide the material required for the reintroduction and restoration of rare and endangered species.

Acer yangbiense is a rare and endangered maple species distributed only in Yunnan Province, China. Zhao et al. [26] found that although the population of A. yangbiense in Yunnan Province contained only five individuals, the population's genetic diversity was high. The authors reported that all of the A. yangbiense seedlings at the time of sampling came from one individual. The presence of three unique alleles in the seedlings indicated that gene flow from other undiscovered A. yangbiense individuals may have occurred. Sun and Yin [27] proposed that $>20$ randomly selected cul- tivated seedlings should be conserved and reintroduced for ex situ conservation. Wang et al. [28] found obvious genetic differences and almost no gene flow among eight populations of Primulina tabacum Hance. This included a large number of inbreed individuals with similar genotypes clustered in these populations. Only two populations of Primulina tabacum exhibit substantial genetic diversity, which should be useful for long-term breeding. Ren et al. [29] successfully reintroduced Primulina tabacum Hance with seedlings generated using tissue culture and derived from two populations.

Tollington et al. [30] found that the genetic diversity of a reintroduced parakeet population declined after 20 years. However, for significant genetic differentiation, augmentation led to genetic homogeneity among sub-populations. Lauterbach et al. [31] suggested that the spatial and temporal isolation associated with ex situ conservation increased genetic differentiation and decreased the genetic diversity of an endangered plant species. Therefore, the establishment of an ex situ conservation site should involve sufficient sampling, capturing the diversity of the in situ population and reducing undesired selection the ex situ environment is similar to the in situ environment [25].

\section{Reintroduction under global climate change}

Global climate change threatens the distribution areas of species, possibly changing the relationship between species and their habitats, particularly endangered species requiring reintroduction. Under climate change, reintroduction should increase the distribution and abundance of a species, improve gene flow, strengthen metapopulation dynamics and reduce the risk of population extinction [22]. Conversely, reintroduction involves risks: the reintroduced species could become invasive because of changes in an ecosystem resulting from climate change. Therefore, to facilitate reintroduction, we should assess following factors in reintroduction: the role of the alien species in their natural ecosystem, habitat fragmentation, climate change, scarcity, protection selection and design in reintroduction [22,32].

Adhikari et al. [33] reported that under climate change scenarios, habitat distribution models should be used to select appropriate sites for the reintroduction of the tree species, Ilex khasiana. Lawrence and Kaye [34] found that for the successful reintroduction of Castilleja levisecta, the materials used should be obtained from ecologically similar habitats rather than geographically proximate to the reintroduction site and that the site should support a low abundance of exotic species. Niche theory suggests that reintroduced species should have an appropriate distribution area and habitat conditions because suitable habitat is a prerequisite for ex situ conservation [18]. However, under climate change scenarios historical or local scope is unnecessary for reintroduction [35]. Traditionally, using locally propagated 
seedlings has been considered the best choice when reintroducing plant species. However, research on the rare and endangered species, Jacquemontia reclinata, indicated that reintroduction success could improve using a variety of seed sources in the event of extreme climatic conditions [36]. Another study reported that the plant material used for reintroduction should be selected for tolerance to herbivores, pests and pathogens because the pressure from these organisms is likely to increase under climate change [37].

Under future climate change conditions, plants will be vulnerable to extinction because they cannot migrate and because their dispersal is typically blocked by mountain barriers. Ren [38] successfully translocated the extremely rare and endangered plant, Tigridiopalma magnifica, from a similar habitat ca. $400 \mathrm{~km}$ from its historical distribution area, indicating that human assisted translocation can be achieved. However, climate change exacerbates the conflicts between protective introduction and social acceptability to reintroduction. Translocation concerns the risks related to the target species while reintroduction management focuses on ecosystem risks. Therefore, the integration of decision-making and technology is important with global climate change $[39,40]$. In addition, translocation will lead to interspecific hybridization. The reintroduction of rare and endangered species may result in adverse genetic or evolution consequences under the substantial incidence of intercontinental species invasion $[41,42]$.

\section{Recruitment: to enhance or limit by means of reintroduction}

Plant reintroduction may assist with establishing a sustainable population. However, inadequate recruitment can limit this process because of inadequate seed quantity, poor seedling germination and survival, and poor reproduction by the next adult generation [43]. In the case of human-assisted recruitment, the number of seeds or seedlings recruited can be limited because of an inadequate source or by insufficient herbivore dispersal. Seed germination and seedling survival can decline if the microsite or habitat is inadequate. These limitations occur when the population is below the carrying capacity, i.e., intraspecific competition does not occur. In the early establishment of the reintroduced species (i.e., during the first 2-3 years of a reintroduction project), any of these limitations can be important [44]. In the establishing forest herbs, a key step was the early arrival of seed, including environmental conditions significantly affecting their being established and colonized [45].

During the reintroduction of rare and endangered species, seedlings of some forest species require either sufficient light or shade, with only some species able to grow in the shade of the understory [18]. Reintroducing rare species in tropical dry rainforests, seeds should be collected at the end of the dry season and sown when the soil is sufficiently moist to increase seedling survival and reduce seed predation [46].

Plant establishment is mainly determined by the seed and its dispersal limit. Seed germination, predation, disease, grazing and resource availability also affect the recruitment process. In forests, light is the critical resource affecting the recruitment, growth and mortality of understory plant species. The understory vegetation determines ongoing tree species composition through this filtering effect [44,47].

The success of plant reintroductions depends on many factors such as: how the planting material is propagated; site selection; the monitoring and management of the material after placement at the site; and the improvement of the soil and other properties at the site. The success of plant reintroductions also depends on the selection of propagule type, habitat features at the site, the geographical location of the original population and the propagule quantity [48]. Ren et al. $[38,49,50]$ found that nurse plant species (species that facilitate the growth and development of the target species under its canopy) can help rare and endangered species overcome recruitment limitations. The nurse plants facilitate target species by providing shade (affecting the extinction coefficient and photosynthetically active radiation), temperature moderation, increased soil water content and nutrient availability (through the litter of nursing plant), reducing herbivory, and influencing symbiotic fungi and nitrogen-fixing bacteria in the soil [51]. Research suggests that the main nursing effect is from the reduced light penetration (shading) and increased soil water content. The soil water content increases because of the shading provided by the nurse plant canopy and the mulch from the nurse plant litter [52].

\section{Reintroduction and ecological restoration}

The evaluation of successful reintroduction projects requires long-term monitoring, including the use of short- and long-term criteria. There are three short-term criteria. First, the reintroduced species should be able to complete its life history at the reintroduction site. Second, the reintroduced species should be able to reproduce and increase in abundance. The population growth rate $(\lambda)$ should be $>1$ for at least one year, with seed production and the developmental stage distribution similar to those of the natural population. Third, the seeds of the reintroduced species should be able to disperse through local media (such as wind, insects and birds), establishing new populations outside of the reintroduction location.

There are four long-term criteria for evaluating reintroductions. First, the reintroduced population should adapt to locally diverse habitats, complete its breeding process using local pollination vectors, establish links with other species, and fulfill the function of the species in the ecosystem. Second, the reintroduced species should establish a mini- 
mum viable breeding population and be self-sustaining. Third, the reintroduced population should be able to recover from natural and human disturbances. Finally, the reintroduced population should maintain a low variation coefficient before it attains an effective population size. As indicated by these criteria, successful reintroduction depends on the integration of the reintroduced species into the ecosystem. Consequently, the reintroduced population can contribute to ecological restoration [24].

When comparing areas occupied by a reintroduced plant species with similar areas within the historical range that were unoccupied, Polak and Saltz [17] determined that plant reintroduction plays a key role in ecosystem restoration and in the reestablishment of ecosystem function. They suggested that the effects on ecosystem functions, including those at the landscape scale, should be examined as part of reintroduction projects.

Reintroduction provides an important opportunity to test concepts concerning population establishment and natural ecosystem management. When selecting a site for reintroduction and beginning the program, managers should consider the site's disturbance history and ecological processes. In addition to considering the requirements of the reintroduced species, reintroduction should consider ecosystem consumers/decomposers, nutrient cycling and energy flow. The goal is to establish all significant ecological links between the population dynamics of the reintroduced species and natural processes [22]. Rayburn [55] suggested that positive interactions between plants can increase the success rate of reintroductions.

Armstrong and Seddon [56] proposed 10 key questions for reintroduction biology. At the population level, they asked the following questions: How is the probability of establishment affected by the size and composition of the release group. How is post-release survival and dispersal affected by pre- and post-release management? What habitat conditions are needed for the persistence of the reintroduced population? How will genetic structure affect the persistence of the reintroduced population? At the metapopulation level: How heavily should source populations be harvested? What is the optimal allocation of translocated individuals among sites? Should translocation be used to compensate for isolation? At the ecosystem level, their questions included are the target species/taxon and its parasites native to the ecosystem? How will the ecosystem be affected by the target species and its parasites? How does the order of reintroductions affect the ultimate species composition?

\section{Prospects}

Reintroductions often fail from the lack of basic and applied research. This situation occurs even though rare and endangered plant species have been reintroduced for many years in the USA, UK, Australia and other developing countries. Rather than simply reporting the results of reintroduction, research should focus on elucidating the mechanisms underlying the successes and failures of reintroductions.

The current practice of monitoring reintroductions is inadequate. This is especially true for failed reintroductions, seldom reported, but their reporting could be highly informative. In addition, monitoring periods are often too short. Godefroid and Vanderborght [58] found that the reintroduction is generally monitored for $<4$ years. They identified several issues including: the descriptions of the reintroduction procedures were often incomplete; the cause of the current population decline was often unclear; insufficient stringent criteria using short-term data; the evaluation of success is often overly optimistic. Godefroid et al. [59] found that the experiences and lessons from reintroductions have not been widely exchanged. The authors suggested the establishment of a network to promote the sharing of results concerning reintroduction.

Montalvo et al. [60] listed five research areas requiring attention in population biology and restoration, with these research areas being highly relevant to plant reintroduction: (i) the influence of numbers of individuals and genetic variation in the initial population on population colonization, establishment, growth, and evolutionary potential; (ii) the role of local adaptation and life history traits in the success of restored populations; (iii) the influence of the spatial arrangement of landscape elements on metapopulation dynamics and population processes such as migration; (iv) the effects of genetic drift, gene flow and selection on population persistence within an often accelerated, successional time frame; (v) the influence of interspecific interactions on population dynamics and community development. In addition, Montalvo et al. [60] highlighted some practical problems such as: inadequate genetic diversity in the donor material selected for reintroduction; the use of non-native germplasm material; genetic bottlenecks; the selection of seed and plant material that are suitable for commercial production but not for reintroduction; lack of mutualists; competition from invasive species.

Managing relocations has become an important strategy for protecting endangered species under climate change, but the risk that the relocated species become invasive has not been evaluated. Our understanding of how relocations should be conducted can be increased using "active adaptive management" and decision theory [61]. Our understanding could be improved if reintroductions were thoroughly documented. For example, Botanic Gardens Conservation International has reintroduced 10 rare tree species in China and the monitoring has mainly focused on population establishment and sustaining growth. However, the metapopulation and ecosystem level processes have seldom been considered but should be documented to obtain the maximum benefits from the reintroduction efforts [20,56].

Improving the success of reintroductions and diversity 
conservation requires greater emphasis on integrating in situ and ex situ conservation, and reintroduction. As part of the reintroduction practice, biotechnology, ecological and engineering technology can be combined, optimizing seed or seedling production, habitat restoration, horticultural measurement and the restoration of interspecies relationships. Jacobs et al. [62] demonstrated this strategy, developing a conceptual framework of technical, ecological, and social factors affecting the restoration of rare and endangered species using the reintroduction of Castanea dentata in America. Jacobs et al. [62] emphasized that restoration, conservation and reintroduction should involve the ecological factors but economic and social factors should also be considered if we are to rebuild a harmonious relationship between human welfare and biodiversity.

This work was supported by the National Key Fundamental Research Development Plan (2009CB421101) and the National Natural Science Foundation of China (40871249, 30670370). We also thank Prof. Bruce Jaffee for improving the manuscript's English.

1 Peng SL. Studies and Practices of Restoration Ecology in Tropical and Subtropical Area. Beijing: Science Press, 2003

2 Ren H, Zhang QM, Lu HF, Liu H, Guo Q, Wang J, Jian S, Bao H. Wild plant species with extremely small populations require conservation and reintroduction in China. AMBIO, 2012, 41: 913-917

3 Secretary of the Convention on biodiversity. The Global Strategy for Plant Conservation. 2005

4 The editorial committee of "China's strategy for plant conservation. China's Strategy for Plant Conservation. Guangzhou: Guangdong Sciences and Technology Press, 2008

5 Ren H. The Theory and Practice of Building Scientific Botanical Gardens. Beijing: Science Press, 2006

6 Huang HW, Zhang Z. The status and prospect of plant introduction and ex-situ conservation in China. Biodiver, 2012, 20: 559-571

7 Maunder M. Plant reintroduction: an overview. Biodivers Conserv, 1992, 1: 51-61

8 Guerrant EO, Kaye TN. Reintroduction of rare and endangered plants: common factors, questions and approaches. Aust J Bot, 2007, 55: $362-370$

9 Griffith B, Scott JM, Carpenter JW, Reed C. Translocation as a species conservation tool: status and strategy. Science, 1989, 245: $477-480$

10 Akeroyd J, Jackson PW. A Handbook for Botanic Gardens on the Reintroduction of Plants to the Wild. Richmond: BGCI, 1995

11 Ren H, Liu Q, Li LH. Introduction to Restoration Ecology. Beijing: Science Press, 2008

12 Zhou X, Gao JY. Reintroduction of rare and endangered plant species: theory and practice. Biodiver, 2011, 19: 97-105

13 Seddon PJ. From reintroduction to assisted colonization: moving along the conservation translocation spectrum. Restor Ecol, 2010, 18: 796-802

14 Council of Europe. Recommendation No. R.(85)15 of the Committee of Ministers on the reintroduction of wildlife species. 4th Meeting. 1985

15 IUCN. Guidelines for Re-introductions. Prepared by the IUCN/SSC Re-introduction Specialist Group. IUCN Gland, Switzerland and Cambridge, UK, 1998

16 IUCN. Guidelines for the in situ Re-introduction and Translocation of African and Asian Rhinoceros. IUCN Gland, Switzerland, 2009

17 Polak T, Saltz D. Reintroduction as an ecosystem restoration technique. Conserv Biol, 2011, 25: 424-425

18 Maschinski J, Haskins KE. Plant Reintroduction in a Changing Cli- mate: Promises and Perils. Washington, DC: Island Press, 2012

19 Albrecht MA, Guerrant EO, Maschinski J, Albrecht MA, Guerrant EO, Maschinski J, Kennedy KL. A long-term view of rare plant reintroduction. Biol Conserv, 2011, 144: 2557-2558

20 Sheean VA, Manning AD, Lindenmayer DB. Armstrong DP, Maloney RF. An assessment of scientific approaches towards species relocations in Australia. Austral Ecology, 2012, 37: 204-215

21 Macdonald DW, Willis KJ, Moehrenschlager A, Shier DM, Moorhouse TP, Price MRS. Righting past wrongs and ensuring the future. Key Topics Conserv Biol, 2013, 2: 405-429

22 Falk DA, Millar CI, Olwell M. Restoring Diversity: Strategies for the Reintroduction of Endangered Plants. Washington, DC: Island Press, 1996

23 Ewen JG, Armstrong DP, Parker KA, Seddon PJ, eds. Reintroduction Biology: Integrating Science and Management. Chichester: John Wiley \& Sons, Ltd., 2012

24 Andel J, Aronson J. Restoration Ecology: The New Frontier. 2nd ed. Blackwell, 2012. 315-359

25 Kang M, Ye QG, Huang HW. Genetic risks in ex-situ conservation of plants. Hereditas (Beijing), 2005, 27: 160-165

26 Zhao LL, Sun WB, Yang JB. Development and characterization of microsatellite markers the critically endangered species Acer yangbiense (Aceraceae). Am J Bot, 2011, 98: e247-e249

27 Sun WB, Yin Q. Ex-situ conserving the Yangbi maple Acer yangbiense in China. Oryx, 2009, 42: 461-462

28 Wang ZF, Ren H, Li ZC, Zhang QM, Liang KM, Ye WH, Wang ZM. Local genetic structure in the critically endangered, cave-associated perennial herb Primulina tabacum (Gesneriaceae). Biol J Linn Society, 2013, 109: 747-756

29 Ren H, Zhang QM, Wang ZF, Guo QF, Wang J, Liu N, Liang KM. Conservation and possible reintroduction of an endangered plant based on an analysis of community ecology: a case study of Primulina tabacum Hance in China. Plant Spec Biol, 2010, 25: 43-50

30 Tollington S, Jones CG, Greenwood A, Tatayahe V, Raisina C, Burkeb T, Dawsonb DA, Groombridgea JJ. Long-term, fine-scale temporal patterns of genetic diversity in the restored Mauritius parakeet reveal genetic impacts of management and associated demographic effects on reintroduction programmes. Biol Conserv, 2013, 161: $28-38$

31 Lauterbach D, Burkart M, Gemeinholzer B. Rapid genetic differentiation between ex situ and their in situ source populations: an example of the endangered Silene otites (Caryophyllaceae). Bot J Linn Soc, 2012, 168: 64-75

32 Hoegh-Guldberg O, Hughes L, McIntyre S, Lindenmayer DB, Parmesan C, Possingham HP, Thomas CD. Assisted colonization and rapid climate change. Science, 2008, 321: 345-346

33 Adhikari E, Barika SK, Upadhaya K. Habitat distribution modelling for reintroduction of Ilex khasiana Purk., a critically endangered tree species of northeastern India. Ecol Eng, 2012, 40: 37-43

34 Lawrence BA, Kaye TN. Reintroduction of Castilleja levisecta: effects of ecological similarity, source population genetics, and habitat quality. Restor Ecol, 2011, 19: 166-176

35 Dalrymple SE, Moehrenschlager A. "Words matter." A response to Jørgensen's treatment of historic range and definitions of reintroduction. Restor Ecol, 2013, 21: 156-158

36 Maschinski J, Wright S J, Koptur S, Pinto-Torres EC. When is local the best paradigm? Breeding history influences conservation reintroduction survival and population trajectories in times of extreme climate events. Biol Conserv, 2013, 159: 277-284

37 Venesky MD, Mendelson JR, Sears BF, Stiling P, Rohr JR. Selecting for tolerance against pathogens and herbivores to enhance success of reintroduction and translocation. Conserv Biol, 2012, 26: 586-592

38 Ren H, Zeng SJ, Li LN, et al. Community ecology and reintroduction of Tigridiopalma magnifica, a rare and endangered herb. Oryx, 2012, 46: 391-398

39 Maunder M, Byers O. Technical guidelines on the management of ex situ populations for conservation. Oryx, 2004, 38: 342-346

40 Schwartz MW, Martin TG. Translocation of imperiled species under 
changing climates. Ann N Y Acad Sci, 2013, 1286: 15-28

41 Guo QF. Intercontinental biotic invasions: what can we learn from native populations and habitats? Biol Invas, 2006, 8: 1451-1459

42 Ricciardi A, Simberloff D. Assisted colonization is not a viable conservation strategy. Trends Ecol Evol, 2009, 24: 248-253

43 Wagenius S, Dykstra AB, Ridley CE, Shaw RG. Seedling recruitment in the long-lived perennial, Echinacea angustifolia: a 10-year experiment. Restor Ecol, 2012, 20: 352-359

44 Ren H, Wang J. Recruitment limitations of native tree species under plantation: a preliminary review. Chin J Appl Ecol, 2007, 18: 1855-1860

45 Godefroid S, Rucquoij S, Koedam N. To what extent do forest herbs recover after clearcutting in beech forest? Forest Ecol Manag, 2005, 210: 39-53

46 Vieira DLM, Scariot A. Principles of natural regeneration of tropical dry forests for restoration. Restor Ecol, 2006, 14: 11-20

47 Wang J, Ren H, Yang L, Duan WJ. Establishment and early growth of introduced indigenous tree species in typical plantations and shrubland in South China. Forest Ecol Manag, 2009, 258: 1293-1300

48 Guerrant EO, Havens K, Maunder M. Ex-situ Plant Conservation: Supporting Species Survival in the Wild. Washington, DC: Island Press, 2004

49 Ren H, Yang L, Liu N. Nurse plant theory and its application in ecological restoration in lower-subtropics of China. Prog Naturl Sci, 2008, 18: 137-142

50 Ren H, Ma GH, Zhang QM, Guo QF, Wang J, Wang ZF. Moss is a key nurse plant for reintroduction of the endangered herb, Primulina tabacum Hance. Plant Ecol, 2010, 209: 313-320

51 Padilla FM, Pugnaire FI. The role of nurse plants in the restoration of degraded environments. Front iEcol Environ, 2006, 4: 196-202

52 Yang L, Ren H, Liu N, Wang J. The shrub Rhodomyrtus tomentosa acts as a nurse plant for seedlings differing in shade tolerance in de- graded land of South China. J Veg Sci, 2010, 21: 262-272

53 Drayton B, Primack RB. Success rates for reintroductions of eight perennial plant species after 15 years. Restor Ecol, 2012, 20: 299-303

54 Pavlik BM. Defining and measuring success. In: Falk DA, Millar CI, Olwell M, eds. Restoring Diversity: Strategies for the Reintroduction of Endangered Plants. Island Press: Washington, DC, 1996. 127-155

55 Rayburn AP. Recognition and utilization of positive plant interactions may increase plant reintroduction success. Biol Conserv, 2011, 144: 1296

56 Armstrong DP, Seddon PJ. Directions in reintroduction biology. Trends Ecol Evol, 2008, 23: 20-25

57 Rout TM, Hauser CE, Possingham HP. Minimise long-term loss or maximise short-term gain? Optimal translocation strategies for threatened species. Ecol Model, 2007, 201: 67-74

58 Godefroid S, Vanderborght T. Plant reintroductions: the need for a global database. Biodivers Conserv, 2011, 20: 3683-3688

59 Godefroid S, Piazza C, Rossi G, Buord S, Stevens AD, Aguraiuja R, Cowell C, Weekley CW, Vogg G, Iriondo JM, Johnson I, Dixon B, Gordon D, Magnanon S, Valentin B, Bjureke K, Koopman R, Vicens M, Virevaire M, Vanderborght T. How successful are plant species reintroductions? Biol Conserv, 2011, 144: 672-682

60 Montalvo AM, Williams SL, Rice KJ. Restoration biology: a population biology perspective. Restor Ecol, 1997, 5: 277-290

61 Rout TM, Hauser CE, Possingham HP. Optimal adaptive management for the translocation of a threatened species. Ecol Appl, 2009, 19: $515-526$

62 Jacobs DF, Dalgleish HJ, Nelson CD. A conceptual framework for restoration of threatened plants: the effective model of American chestnut (Castanea dentata) Reintroduction. New Phytol, 2013, 197: 378-393

Open Access This article is distributed under the terms of the Creative Commons Attribution License which permits any use, distribution, and reproduction in any medium, provided the original author(s) and source are credited. 